\title{
Magnitude of, and Factors Associated with Cardiovascular Disease Among Type Two Diabetes Mellitus Patients
}

This article was published in the following Dove Press journal: Diabetes, Metabolic Syndrome and Obesity: Targets and Therapy

\author{
Adane Tesfaye $\mathbb{D}^{\prime}$ \\ Haileyesus Josef' \\ Temesgen Bizuayehu Wube (D) $^{2}$ \\ Zeleke Girma $\mathbb{D D}^{\prime}$ \\ Belay Negasa $\mathbb{D}^{\prime}$ \\ Temesgen Muche ${ }^{1}{ }^{1}$ \\ Bewnetu Zewude ${ }^{3}$
}

'Department of Public Health, School of Public Health, College of Medicine and Health Science, Dilla University, Dilla, Ethiopia; ${ }^{2}$ School of Medical Laboratory Science, College of Medicine and Health Science, Hawassa University, Hawassa, Ethiopia; ${ }^{3}$ Department of Sociology, College of Social Science, Wolaita Sodo University, Wolaita Sodo, Ethiopia
Correspondence: Temesgen Bizuayehu Wube

School of Medical Laboratory Science, College of Medicine and Health Science, Hawassa University, P.o Box I560,

Hawassa, Ethiopia

Tel +25|9-|6-60-45-5|

Email temesgenbuizuayehu2@gmail.com
Background: Diabetes mellitus is becoming one of the major health problems in developing countries. The number of adults living with type 2 diabetes mellitus (T2DM) worldwide is increasing over time. Cardiovascular disease (CVD) is the major cause of death in T2DM. The objective of this study was to determine the prevalence of cardiovascular disease and its associated factors among diabetic patients at the MRC clinic of Dilla University Referral Hospital (DURH).

Methods: A hospital-based cross-sectional study was conducted from April to May 2019 . A total of 216 diabetic individuals were selected with a convenient sampling technique from patients on follow-up at DURH MRC. Data were collected using a structured format. The diagnosis of CVD was made with the necessary diagnostic tests and examination. The data analysis was done in SPSS software version 20. Bivariate and multivariable logistic regression analysis was carried out to identify factors associated with cardiovascular disease.

Results: A total of 216 patients participated in the study and the mean age of the study participants was 30 years; $83.3 \%$ of the study participants were male. The overall prevalence of cardiovascular disease was $25 \%$ of which $57 \%$ were ischemic heart disease, $32 \%$ were hypertensive and $10 \%$ were stroke. Duration of DM for more than 10 years and diabetic drug discontinuation were factors associated with cardiovascular disease. Odds of CVD was nearly four times more in those whose duration of $\mathrm{DM}$ is more than 10 years $(\mathrm{AOR}=4.00$, 95\% CI: 2.386-6.705) and odds of CVD among those who discontinued medication were almost three times more, $(\mathrm{AOR}=2.98,95 \% \mathrm{CI}: 1.287-6.080)$.

Conclusion: A quarter of the diabetic population studied developed CVD. Duration of DM for more than 10 years and drug discontinuation are independent associated factors of CVD. Hence appropriate intervention at early stages should be implemented at primary healthcare level.

Keywords: T2DM, cardiovascular disease, Ethiopia

\section{Introduction}

The International Diabetes Federation (IDF) estimates that worldwide, 415 million people have diabetes, $91 \%$ of whom have type 2 diabetes mellitus (T2DM). People with diabetes comprise $8.8 \%$ of the world's population, and the number of cases of diabetes is predicted to rise to 642 million by $2040 .^{1,2}$ Individuals with T2DM and with chronically poor metabolic control can experience microvascular and macrovascular complications leading to a significant burden for the individual and for society. This burden includes direct costs of medical care and indirect costs, such as loss of 
productivity, which result from T2DM-related morbidity and premature mortality. ${ }^{3-5}$ Insulin resistance preceding long before the diagnosis of T2DM enhances atherogenic risk profile and has been delineated as a potential cause for subsequent increased risk of cardiovascular disease (CVD) among diabetic patients. ${ }^{6}$

Patients with T2DM disease are disproportionately affected by CVD compared with those without diabetes. ${ }^{7-10}$ CVD is a major cause of disability among people with $\mathrm{T}_{2} \mathrm{DM}^{2,11}$ and accounts for more than one-half of all the deaths due to T2DM. ${ }^{12,13}$ In persons with T2DM, the death rates were $15.4 \%$ for those with no prior myocardial infarction (MI) and $42.0 \%$ in patients having a history of MI which is in contrast with patients who did not have T2DM. ${ }^{10}$ Specifically, coronary artery disease (CAD) was most lethal, followed by stroke. ${ }^{14} \mathrm{~A}$ meta-analysis by Einarson et al. showed that atherosclerosis $(29.1 \%)$ is the most prevalent CVD followed by CAD (21.2\%) and heart failure (14.9\%). ${ }^{15}$ Furthermore, diabetic patients with CVD have a worse prognosis for survival than CVD patients without T2DM and their quality of life also depreciates.

The elevated risk of cardiovascular events among diabetic versus non-diabetic patients emphasizes the need for screening of asymptomatic diabetic patients for CVD risk by the premise that earlier identification and stratification would lead to appropriate management of cardiovascular risk in both the long and short term.

There is a scarcity of comprehensive data on the prevalence and associated factors of CVD among patients with T2DM in Ethiopia, specifically in the study region. This study was therefore conducted to assess the prevalence of CVD and its associated factors among T2DM patients on follow-up at the diabetic clinic (MRC) of Dilla University Referral Hospital, Ethiopia.

\section{Materials and Methods Study Setting and Design}

This was a hospital-based cross-sectional study conducted in Dilla University Referral Hospital, which is in Dilla Town, located $360 \mathrm{~km}$ away from the capital city, Addis Ababa, and $90 \mathrm{~km}$ from Hawassa in southern Ethiopia. Dilla University Referral Hospital serves a population of over 100,000 who are mainly $(80 \%)$ rural. The hospital contains approximately 200 beds that provide surgical, gynecologic/obstetric, medical, and pediatric wards. It acts as a referral center for the surrounding primary healthcare units. The study period was from April to May 2019.

\section{Study Population}

The sample size was computed using a single population proportion formula, with the following assumptions: $95 \%$ confidence level to be 1.96, degree of precision (d) to be 0.05 , and adding $10 \%$ for non-response yielding a sample size of 216. All selected adult diabetic patients who visited chronic medical outpatients department at Dilla University Referral Hospital during the study period made up the study population. Patients who were critically ill and unable to communicate during the interview were excluded.

\section{Socio-Demographic and Clinical Data Collection}

Socio-demographic data such as age, sex, residency and educational status, clinical data such as blood pressure and anthropometric related data of the study participants were collected using a structured questionnaire including a review of patients' clinical records. Data were collected by face to face interview, followed by measurement of fasting blood glucose, blood pressure, height, and weight.

Systolic blood pressure (SBP) and diastolic blood pressure (DBP) were measured from each subject with a standard adult arm cuff (sphygmomanometer). Two trained medical doctors who were working in the chronic diseases follow-up clinic measured the blood pressure from the right arm after a patient had rested for at least 5 minutes. The precision of the measurement was checked by using two readings two minutes apart and the average of the two readings was taken as blood pressure.

Diagnosis of CVD was made by the necessary diagnostic tests and examination. Anthropometric data (weight and height) were collected according to WHO guidelines. Weight was measured using a digital bath balance, Seca, which is a German model for weight measurement. A portable height measuring device with standing scale which was calibrated regularly against known weight and recorded to the nearest $0.1 \mathrm{~kg}$ was used. Body mass index (BMI) was calculated with the weight divided by the square of height in kilogram per meters square formula $\left(\mathrm{BMI}=\right.$ weight $/ \mathrm{height}^{2}$ in $\left.\mathrm{kg} / \mathrm{m}^{2}\right)$. The patients were classified on the basis of body mass index (BMI) using WHO classification. ${ }^{16}$

Dyslipidemia was defined by the presence of more than one abnormal serum lipid concentration and hyperglycemia was defined as having fasting blood glucose level $>110 \mathrm{mg} / \mathrm{dL}$. 


\section{Data Processing and Analysis}

Socio-demographic and economic data were cleaned manually and then entered into the computer using EPI Info version 7 and statistical analysis was carried out using SPSS version 20, with descriptive summary used to summarize the variable. Continuous variables such as age and income were first transformed into categorical variables before they were analyzed. First, the frequency of all the variables in the questionnaire was determined. Secondly, cross-tabulation was done between important variables, their significance was checked by bivariate analysis and multivariable logistic regression was done to assess the association of factors. Variables with a p-value of less than 0.2 in the bivariate analysis were entered into the final model. Important variables were entered and analyzed using multivariable logistic regressions to find factors associated with CVD among T2DM. Finally, the results of the study were presented using graphs and tables. In all cases, a p-value of $<0.05$ was considered statistically significant.

\section{Results}

\section{Socio-Economic, Demographic and Other Characteristics}

Out of the 216 study participants, the mean age of the study participants was 30 years and $126(58.3 \%)$ were older than 30 years. Most 180 (83.3\%) were male and $162(75 \%)$ were urban residents. $36(16.7 \%)$ had no formal education while 54 (25\%) were degree holders. 72 (33.3\%) were farmers and $90(41.7 \%)$ earned more than 2500 birr and $126(58.3 \%)$ were married (Table 1).

About 90 (41.7\%) were leading a sedentary life or were physically inactive and $38.5 \%$ were overweight (BMI $>25)$. About $72(33.3 \%)$ were cigarette smokers whereas 54 were khat chewers and another 54 (25\%) were alcohol drinkers regularly.

\section{Prevalence of CVD Among the Study Participants}

The total prevalence of CVD among the study participants was $25 \%$ and $50 \%$ of the study participants were hypertensive. $41.7 \%$ had dyslipidemia and $16.7 \%$ had a family history of chronic illness. $33.3 \%$ had DM for more than 10 years and $33.3 \%$ of the study participants had diabetic drug discontinuation history (Table 2).
Table I Socio-Demographic Characteristics of Diabetic Patients on Follow-Up at DURH, April to May, 2019

\begin{tabular}{|c|c|c|c|}
\hline Variables & Category & Frequency & Percent \\
\hline \multirow[t]{3}{*}{ Age } & $<30$ years & 90 & 41.7 \\
\hline & $>30$ years & 126 & 58.3 \\
\hline & Total & 216 & 100 \\
\hline \multirow[t]{3}{*}{ Sex } & Male & 180 & 83.3 \\
\hline & Female & 36 & 16.7 \\
\hline & Total & 216 & 100 \\
\hline \multirow[t]{6}{*}{ Educational Status } & Uneducated & 36 & 16.7 \\
\hline & Grade I-8 & 36 & 16.7 \\
\hline & Grade $9 \&$ above & 18 & 8.3 \\
\hline & Diploma & 72 & 33.3 \\
\hline & Degree & 54 & 25 \\
\hline & Total & 216 & 100 \\
\hline \multirow[t]{3}{*}{ Marital Status } & Married & 126 & 58.3 \\
\hline & Divorced & 90 & 41.7 \\
\hline & Total & 216 & 100 \\
\hline \multirow[t]{3}{*}{ Residency } & Urban & 162 & 75 \\
\hline & Rural & 54 & 25 \\
\hline & Total & 216 & 100 \\
\hline \multirow[t]{4}{*}{ Occupation } & Farmer & 72 & 33.3 \\
\hline & Employed & 90 & 41.7 \\
\hline & Jobless & 54 & 25 \\
\hline & Total & 216 & 100 \\
\hline \multirow[t]{4}{*}{ Income } & Less than $1000 \mathrm{birr}$ & 72 & 33.3 \\
\hline & $1000-2500$ birr & 54 & 25 \\
\hline & More than 2500 birr & 90 & 41.7 \\
\hline & Total & 216 & 100 \\
\hline
\end{tabular}

\section{Factors Associated with CVD Among T2DM Patients}

Age, occupation, family medical history of DM, alcohol drinking, drug discontinuation, duration of treatment, physical inactivity and obesity/overweight were found to be associated with CVD at bivariate level analysis. Drug discontinuation and duration of treatment for more than 10 years remained statistically significant at multivariable analysis level with $95 \% \mathrm{CI}$ $(\mathrm{AOR}=4.0, \quad \mathrm{CI}=2.0-8.0, \mathrm{P}=0.02) \quad$ and $\quad(\mathrm{AOR}=3.0$, $\mathrm{CI}=1.3-6.1, \mathrm{P}=0.03)$ respectively. The odds of $\mathrm{CVD}$ among those who discontinued medication are four times more than those who did not discontinue their medication. The odds of CVD among those who were on DM treatment for more than 10 years is almost three times higher than those who were on treatment for less than 5 years (Table 3 ). 
Table 2 Clinical Characteristics of Diabetic Patients on FollowUp at DURH, April to May, 2019

\begin{tabular}{|c|c|c|c|}
\hline Independent Variables & & Frequency & Percent \\
\hline $\begin{array}{l}\text { Ever Diagnosed with } \\
\text { CVD? }\end{array}$ & $\begin{array}{l}\text { Yes } \\
\text { No } \\
\text { Total }\end{array}$ & $\begin{array}{l}54 \\
162 \\
216\end{array}$ & $\begin{array}{l}25.0 \\
75.0 \\
100.0\end{array}$ \\
\hline $\begin{array}{l}\text { Ever Diagnosed } \\
\text { Hypertension? }\end{array}$ & $\begin{array}{l}\text { Yes } \\
\text { No } \\
\text { Total }\end{array}$ & $\begin{array}{l}108 \\
108 \\
216\end{array}$ & $\begin{array}{l}50.0 \\
50.0 \\
100.0\end{array}$ \\
\hline $\begin{array}{l}\text { Ever Diagnosed } \\
\text { Dyslipidemia? }\end{array}$ & $\begin{array}{l}\text { Yes } \\
\text { No } \\
\text { Total }\end{array}$ & $\begin{array}{l}90 \\
126 \\
216\end{array}$ & $\begin{array}{l}41.7 \\
58.3 \\
100.0\end{array}$ \\
\hline $\begin{array}{l}\text { Past History Medical } \\
\text { Illness }\end{array}$ & $\begin{array}{l}\text { Yes } \\
\text { No } \\
\text { Total }\end{array}$ & $\begin{array}{l}36 \\
180 \\
216\end{array}$ & $\begin{array}{l}16.7 \\
83.3 \\
100.0\end{array}$ \\
\hline $\begin{array}{l}\text { Family History of Chronic } \\
\text { Illness }\end{array}$ & $\begin{array}{l}\text { Yes } \\
\text { No } \\
\text { Total }\end{array}$ & $\begin{array}{l}36 \\
180 \\
216\end{array}$ & $\begin{array}{l}16.7 \\
83.3 \\
100.0\end{array}$ \\
\hline Duration of DM & $\begin{array}{l}<5 \text { years } \\
5-10 \text { years } \\
\text { More than } \\
10 \text { years } \\
\text { Total }\end{array}$ & $\begin{array}{l}90 \\
54 \\
72 \\
216\end{array}$ & $\begin{array}{l}41.7 \\
25.0 \\
33.3 \\
\\
100\end{array}$ \\
\hline $\begin{array}{l}\text { Diabetic Drug } \\
\text { Discontinuation History }\end{array}$ & $\begin{array}{l}\text { Yes } \\
\text { No } \\
\text { Total }\end{array}$ & $\begin{array}{l}72 \\
144 \\
216\end{array}$ & $\begin{array}{l}33.3 \\
66.7 \\
100\end{array}$ \\
\hline IHD & $\begin{array}{l}\text { Yes } \\
\text { No } \\
\text { Total }\end{array}$ & $\begin{array}{l}16 \\
12 \\
28\end{array}$ & $\begin{array}{l}57 \\
43 \\
100\end{array}$ \\
\hline HHD & $\begin{array}{l}\text { Yes } \\
\text { No } \\
\text { Total }\end{array}$ & $\begin{array}{l}9 \\
19 \\
28\end{array}$ & $\begin{array}{l}32 \\
68 \\
100\end{array}$ \\
\hline Stroke & $\begin{array}{l}\text { Yes } \\
\text { No } \\
\text { Total }\end{array}$ & $\begin{array}{l}3 \\
25 \\
28\end{array}$ & $\begin{array}{l}10 \\
90 \\
100\end{array}$ \\
\hline
\end{tabular}

Abbreviations: CVD, cardiovascular disease; DM, diabetes mellitus; HHD, hypertensive heart disease; IHD, ischemic heart disease.

\section{Discussion}

This study aimed to assess the prevalence of CVD and its associated factors among T2DM patients. $83.3 \%$ of the study participants were male and $75 \%$ of them resided in urban areas. $41.7 \%$ and $50 \%$ of the study participants had dyslipidemia and hypertension, respectively. The prevalence of CVD among the study participants is $25 \%$. Duration of DM and unnecessary diabetic drug discontinuation are independent predictors of CVD among DM patients.
The prevalence of CVD among the study participants is $25 \%$ which is in agreement with reports from Cameroon (28.6\%) and Southeast Asia (29.5\%), ${ }^{17}$ but lower than reported in a systematic literature review on the prevalence of cardiovascular disease in T2DM, which revealed the highest prevalence of overall CVD in North America and the Caribbean (46.0\%), Southeast Asia (42.5\%) and the Western Pacific (including China) $(33.6 \%)^{15}$ That review also reported a pooled prevalence of $32.2 \%$ of CVD. ${ }^{15}$ This difference could be due to the inclusion of diabetics under the age of 18 in the systematic review and differences in the study settings, study time, stage and types of overt complication of T2DM at which the data were collected. It also could be because of lifestyle differences of the study participants, which will be related with the each county's development index as most of the studies included in the meta-analysis were from developed countries.

The high prevalence of CVD in the current study may cause increased morbidity and mortality among diabetic patients due to the synergism of hyperglycemia with other cardiovascular risk factors. ${ }^{18}$ The prevalence of dyslipidemia among the study participants was $41.7 \%$ which is relatively comparable with a follow-up study done on a Korean population (49.5\%) and DIAB-CORE project (49.4\%). ${ }^{19}$ The current studyresults were much lower than the study done in Durame general hospital, Ethiopia $(65.6 \%),{ }^{20}$ in Tanzania $(94.1 \%)^{21}$ and Pakistan $(95 \%){ }^{22}$ Another study also found dyslipidemia among hyperglycemic patients to be $92.4 \% .{ }^{23}$ The high prevalence could be explained by genetic differences, difference in study setup or because of the method used to classify dyslipidemia. ${ }^{24,25}$

In the current study $50 \%$ of participants were hypertensive which is higher than the study done in southern Ethiopia $(25.5 \%)^{26}$ and lower than the study done from DIAB-CORE project data (83.9\%). ${ }^{19}$ The difference could be explained by a difference in lifestyle, study setup, genetics and mean age of the participants. We also cannot exclude cases of elevated blood pressure caused by the stress of the unfamiliar situation.

Duration of DM and unnecessary diabetic drug discontinuation are independent predictors of CVD among DM patients. This is because the longer duration of DM and drug discontinuation brought about hyperglycemia which is an important etiologic factor leading to complications of DM. The mechanism by which hyperglycemia leads to diverse cellular and organ dysfunction may be explained by hyperglycemia-induced increased production of reactive oxygen 
Table 3 Bivariate and Multivariable Analysis of the Associations Between Selected Characteristics and the CVD Risk Factors in Diabetic Patients, DURH, April to May 2019

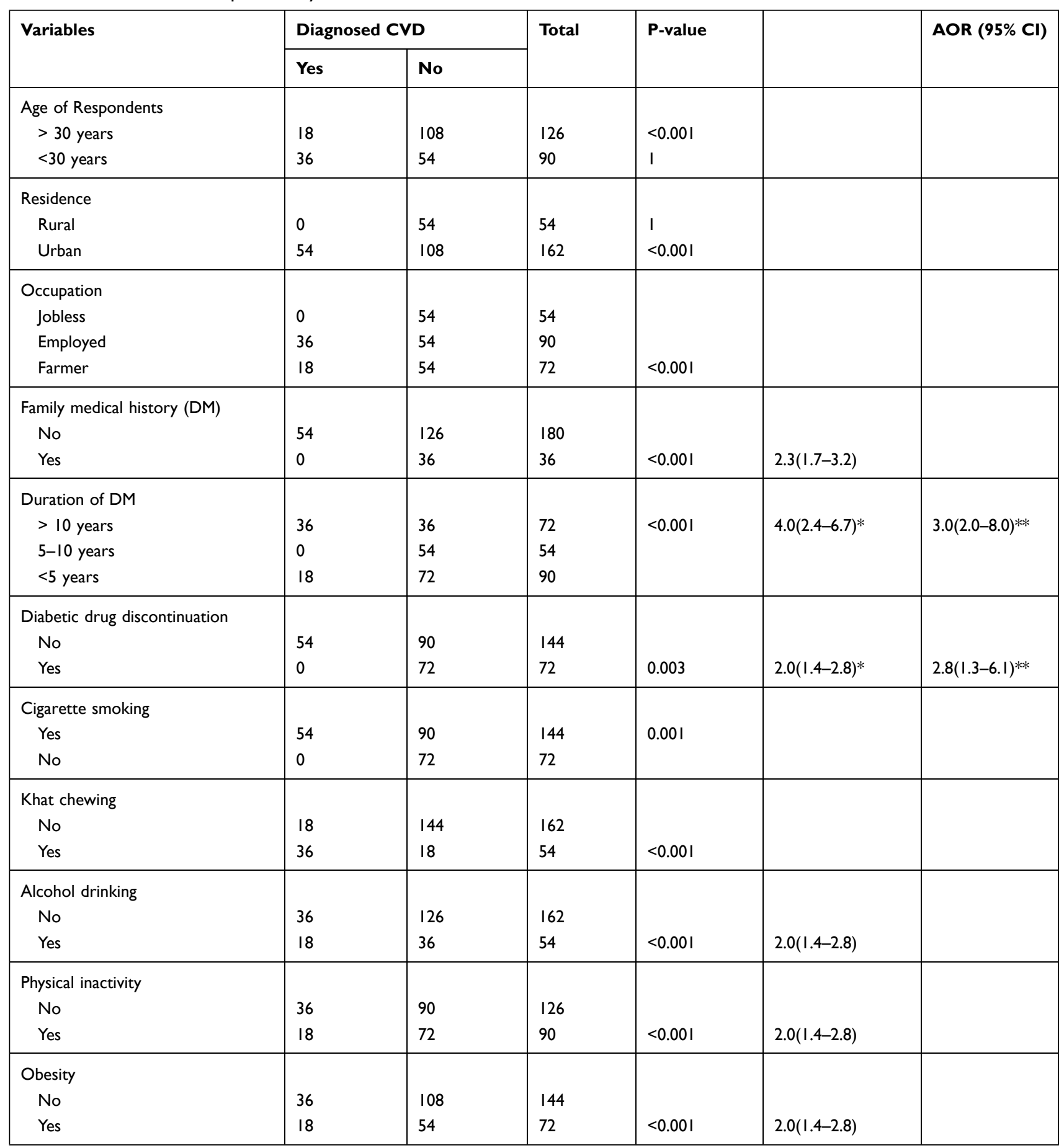

Notes: *P-value $<0.2 ;{ }^{* *}$-value $<0.05$.

species or superoxide in the mitochondria causing different cytotoxicity in the cellular level and organ dysfunction. ${ }^{18}$

\section{Limitation}

The authors could not generalize the findings of the present study to the entire population as the current study was small in sample size and cross-sectional in study design. These findings need to be validated further through various epidemiological study designs, large sample sizes, and inclusion of various other sociodemographic and biological parameters. Moreover measurements of blood pressure and lipids based on a single 
testing opportunity provide evidence for the respective condition only.

\section{Conclusion}

A quarter of the diabetic population developed CVD. Duration of DM for more than 10 years and drug discontinuation are independent predictors of CVD.

\section{Abbreviations}

BMI, Body mass index; CVD, Cardiovascular disease; DM, Diabetes Mellitus; DURH, Dilla University Referral Hospital; HDL, High-density lipoprotein; HHD, hypertensive heart disease; IDF, International Diabetes Federation; IHD, ischemic heart disease; RBS, Random blood sugar; MRC, Medical referral clinic; MRFIT, Multiple risk factors intervention trials; WHO, World Health Organization.

\section{Ethics Approval and Consent to Participate}

This study was conducted in accordance with the Declaration of Helsinki. The study was approved by Dilla University, Internal Review Board. An official letter of cooperation was written from Dilla University College of Health Science to all concerned bodies. The aim, purpose, benefits and method of the study were clearly explained to the participants. The entire study participants had been informed that, the data obtained from them were used only for this study purpose, the confidentiality of the data were maintained and their names were not recorded. Next, the study participants was informed that they can withdraw from the study at any time and being withdrawn would not have any negative impact on their diagnosis and treatment in the hospital. Finally, each study participant had provided a signed consent before any data were collected.

\section{Acknowledgments}

Authors express their special thanks to all DM patients who took part in the study and all the staff of Dilla University Referral Hospitals, data collectors and supervisors who sacrificed their precious time for the success of this study.

\section{Author Contributions}

All authors made substantial contributions to conception and design, acquisition of data, or analysis and interpretation of data; took part in drafting the article or revising it critically for important intellectual content; gave final approval of the version to be published; and agree to be accountable for all aspects of the work.

\section{Disclosure}

The authors report no conflicts of interest in this work.

\section{References}

1. Abraham TM, Pencina KM, Pencina MJ, Fox CS. Trends in diabetes incidence: the Framingham heart study. Diab Care. 2015;38:482-487. doi:10.2337/dc14-1432

2. International Diabetes Federation. IDF Diabetes Atlas. 7th ed. Brussels: International Diabetes Federation; 2015.

3. American Diabetes Association. Economic costs of diabetes in the US in2007. Diabetes Care. 2008;31:596-615. doi:10.2337/dc08-9017

4. International Diabetes Federation. Diabetes Atlas, International Diabetes Federation Diabetes Atlas. 3rd ed. Brussels, Belgium; 2006.

5. Bahia LR, Araujo DV, Schaan BD, et al. The costs of type ' 2 diabetes mellitus outpatient care in the Brazilian public health system. Value Health. 2011;14:137-140.

6. Eddy D, Schlessinger L, Kahn R, Peskin B, Schiebinger R. Relationship of insulin resistance and related metabolic variables to coronary artery disease: a mathematical analysis. Diabetes Care. 2009;32(2):361-366. doi:10.2337/dc08-0854

7. Sarwar N, Gao P, Seshasai SR, et al. Diabetes Mellitus, fasting blood glucose concentration, and risk of vascular disease: a collaborative meta-analysis of 102 prospective studies emerging risk factors collaboration. Lancet. 2010;375:2215-2222.

8. Orasanu G, Plutzky J. The pathologic continuum of diabetic vascular disease. J Am Coll Cardiol. 2009;53(5):35-42.

9. Singh GM, Danaei G, Farzadfar F, et al. The age-specific quantitative effects of metabolic risk factors on cardiovascular diseases and diabetes: a pooled analysis. PLoS One. 2013;8.

10. Haffner SM, Lehto S, Rönnemaa T, Pyörälä K, Laakso M. Mortality from coronary heart disease in subjects with type 2 diabetes and nondiabetic subjects with and without prior myocardial infarction. $N$ Engl J Med. 1998;339:229-234. doi:10.1056/NEJM1998072 33390404

11. Einarson TR, Acs A, Ludwig C, Panton UH. Prevalence of cardiovascular disease in type 2 diabetes: a systematic literature review of scientific evidence from across the world in 2007-2017. Cardiovasc Diabetol. 2018;17(1):83. doi:10.1186/s12933-018-0728-6

12. Fox CS, Pencina MJ, Wilson PW, Paynter NP, Vasan RS, D'Agostino RB. The lifetime risk of cardiovascular disease among individuals with and without diabetes stratified by obesity status in the Framingham heart study. Diab Care. 2008;31:1582-1584. doi: $10.2337 / \mathrm{dc} 08-0025$

13. Morrish NJ, Wang SL, Stevens LK, Fuller JH, Keen H. Mortality and causes of death in the WHO multinational study of vascular disease in diabetes. Diabetologia. 2001;44(1):14-21.

14. Straka RJ, Liu LZ, Girase PS, DeLorenzo A, Chapman RH. Incremental cardiovascular costs and resource use associated with diabetes: an assessment of 29,863 patients in the US managed-care setting. Cardiovasc Diabetol. 2009;8(1):53. doi:10.1186/1475-2840$8-53$

15. Einarson TR, Acs A, Ludwig C, Panton UH. Prevalence of cardiovascular disease in type 2 diabetes: a systematic literature review of scientific evidence from across the world in 2007-2017. BMC Cardiovasc Diabetol. 2018;17(83):1-19.

16. World Health Organization. Diet, nutrition and prevention of chronic disease. Report of a joint WHO/FAO expert consultation. Tech Rep. 2003;916. 
17. Mareeswaran N, Savitha AK, Gopalakrishnan S. Prevalence of intestinal parasites among urban and rural population in Kancheepuram district of Tamil Nadu. Int J Community Med Public Health. 2018;5 (6). doi:10.18203/2394-6040.ijcmph20182199

18. Harrison, the principle of internal medicine, 20th ED. 2018;20:3137-3142

19. Rückert I-M, Maier W, Mielck A, et al. Personal attributes that influence the adequate management of hypertension and dyslipidemia in patients with type 2 diabetes. Results from the DIAB-CORE Cooperation Cardiovascular Diabetology. 2012;11:120.

20. Bekele S, Yohannes T, Eshete A. Dyslipidemia and associated factors among diabetic patients attending Durame General Hospital in Southern Nations, Nationalities, and People's Region. Diabetes Metabol Syndr Obesity. 2017;10:265-271. doi:10.2147/DMSO.S135064

21. Nyasatu GC, Elichilia R, Tolbert S, Isaack AL. Lipid profile of Type 2 diabetic patients at a tertiary hospital in Tanzania: cross sectional study. J Endocrinol Diabetes. 2017;4(1):1-6.

22. Sarfraz M, Sajid S, Ashraf MA. Prevalence and pattern of dyslipidemia in hyperglycemic patients and its associated factors among Pakistani population. Saudi J Biol Sci. 2016;23:761-766. doi:10.1016/j.sjbs.2016.03.001
23. Jayarama N, Reddy M, Lakshmaiah V. Prevalence and pattern of dyslipidemia in type 2 diabetes mellitus patients in a rural tertiary care centre, South India. GJMEDPH. 2012;1(3):24.

24. Noh J, Han KD, Ko SH, Ko KS, Park CY. Trends in the pervasiveness of type 2 diabetes, impaired fasting glucose and co-morbidities during an 8-year-follow-up of nationwide Korean population. Sci Rep. 2017;7(46656):1-7. doi:10.1038/srep46656

25. Arca M, Pigna G, Favoccia C. Mechanisms of diabetic dyslipidemia: relevance for atherogenesis. Curr Vasc Pharmacol. 2012;10:684-686. doi:10.2174/157016112803520864

26. Woyesa SB, Hirigo AT, Wube TB. Hyperuricemia and metabolic syndrome in type 2 diabetes mellitus patients at Hawassa university comprehensive specialized hospital, South West Ethiopia. BMC Endocr Disord. 2018;17:76. doi:10.1186/s12902-017-02 $26-\mathrm{y}$

\section{Publish your work in this journal}

Diabetes, Metabolic Syndrome and Obesity: Targets and Therapy is an international, peer-reviewed open-access journal committed to the rapid publication of the latest laboratory and clinical findings in the fields of diabetes, metabolic syndrome and obesity research. Original research, review, case reports, hypothesis formation, expert opinion and commentaries are all considered for publication. The manuscript management system is completely online and includes a very quick and fair peer-review system, which is all easy to use. Visit http://www.dovepress.com/testimonials.php to read real quotes from published authors. 